\title{
The Netrin-1/DCC guidance system: dopamine pathway maturation and psychiatric disorders emerging in adolescence
}

\author{
Daniel E. Vosberg ${ }^{1,2,5} \cdot$ Marco Leyton ${ }^{1,2,3} \cdot$ Cecilia Flores ${ }^{1,2,3,4}$
}

Received: 26 April 2019 / Revised: 1 August 2019 / Accepted: 19 August 2019 / Published online: 28 October 2019

(c) The Author(s) 2019. This article is published with open access

\begin{abstract}
Axon guidance molecules direct growing axons toward their targets, assembling the intricate wiring of the nervous system. One of these molecules, Netrin-1, and its receptor, DCC (deleted in colorectal cancer), has profound effects, in laboratory animals, on the adolescent expansion of mesocorticolimbic pathways, particularly dopamine. Now, a rapidly growing literature suggests that (1) these same alterations could occur in humans, and (2) genetic variants in Netrin-1 and DCC are associated with depression, schizophrenia, and substance use. Together, these findings provide compelling evidence that Netrin-1 and DCC influence mesocorticolimbic-related psychopathological states that emerge during adolescence.
\end{abstract}

\section{Objectives}

The human brain is interconnected by an estimated 10 million $\mathrm{km}$ of neurites [1]. The specific routes taken are choreographed by a surprisingly small number of axon guidance molecules [2]. In this review, we summarize evidence that recently identified mutations and common variants of genes encoding the guidance cue Netrin-1 and its receptor, DCC (deleted in colorectal cancer), affect the adolescent expansion of mesocorticolimbic dopamine pathways and vulnerability to putative mesocorticolimbicrelated psychiatric disorders.

Marco Leyton

marco.leyton@mcgill.ca

$\triangle$ Cecilia Flores

cecilia.flores@mcgill.ca

1 Department of Psychiatry, McGill University, Montreal, QC, Canada

2 Integrated Program in Neuroscience (IPN), McGill University, Montreal, QC, Canada

3 Neurology and Neurosurgery, McGill University, Montreal, QC, Canada

4 Douglas Mental Health University Institute, Montreal, QC, Canada

5 Present address: Population Neuroscience and Developmental Neuroimaging, Bloorview Research Institute, Holland Bloorview Kids Rehabilitation Hospital, Toronto, ON, Canada

\section{Mesocorticolimbic dopamine anatomy and psychiatric disorders}

The primate mesocorticolimbic dopamine system shares many features with the homologous pathways in rodents. As in rodents, primate dopamine cells project from the upper brainstem to the dorsal striatum and multiple cortical and subcortical limbic regions [3, 4]. These latter targets include the ventral striatum (nucleus accumbens (NAcc), olfactory tubercle), septum, hippocampus, amygdala, and cortical regions, particularly the prefrontal (PFC), cingulate, and perirhinal cortices. Primates and rodents both have descending glutamatergic and GABAergic projections from the anterior cingulate and orbital frontal cortices to several limbic and midbrain regions, including the ventral striatum and the dopamine cell body regions, the substantia nigra (SN) and ventral tegmental area (VTA) [3, 5]. In both rodents and primates, the density of mesocortical dopamine fibers increases dramatically from adolescence to adulthood $[6,7]$. This process, at least in rodents, results from dopamine axons continuing to grow beyond the NAcc to the PFC across adolescence [8]. Compared to rodents, primate cortical dopamine projections are more widespread [9], innervating the entire cortical mantle, albeit more to anterior than posterior regions $[10,11]$. Subcortical dopamine axons are often myelinated in primates, a feature not seen in rodents [10].

Disturbances to mesocorticolimbic development have been proposed to contribute to multiple psychiatric disorders. Consistent with this hypothesis, dopamine neurotransmission and mesocorticolimbic functional connectivity 
Fig. 1 a DCC-mediated Netrin-1 connectivity-related processes. Throughout adolescent brain development, target recognition, axon arborization, and synapse formation are ongoing including dopamine axon targettting, long distance axonal growth, and synaptogenesis by mesocorticolimbic dopamine axons. Green gradients indicate Netrin-1 and the depicted axons express DCC. b Dcc Mutation Behavioral Effects in Mice. Ages, in post-natal days $(\mathrm{P})$, and periods (early adolescence, mid adolescence, and adulthood) at which stimulant drug-induced effects on reward and information processing emerge in $D c c$ haploinsufficient mice.

The effects are in green, based on studies of $D c c$

haploinsufficient mice [6,7].

c Age of Onset of $D C C$ -

implicated Psychiatric

Disorders. The DCC-implicated psychiatric disorders, major depressive disorder, schizophrenia, and substance use disorder, begin to emerge in adolescence. The interquartile ranges (25th to 75 th percentiles) are indicated in green. The median ages of onset for major depressive disorder, schizophrenia, and substance use disorder are 32, 23, and 20, respectively. Data to construct the figure were obtained from a U.S. survey and an international review $[17,18]$
A

DCC-Mediated Netrin-1 Connectivity-Related Processes

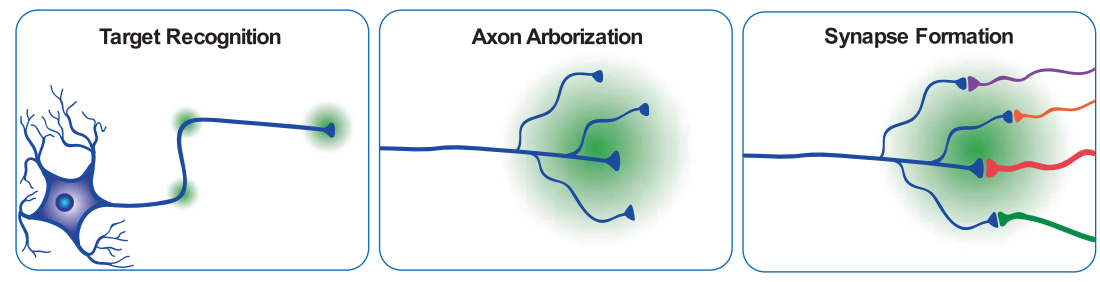

B

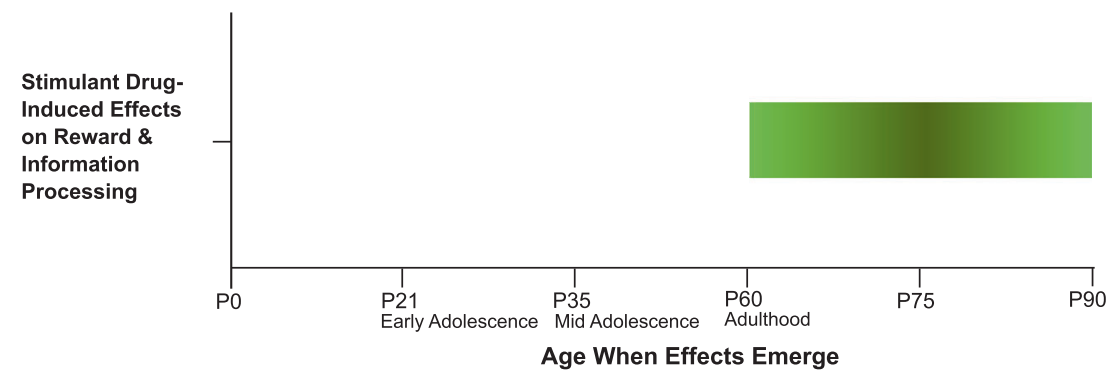

C

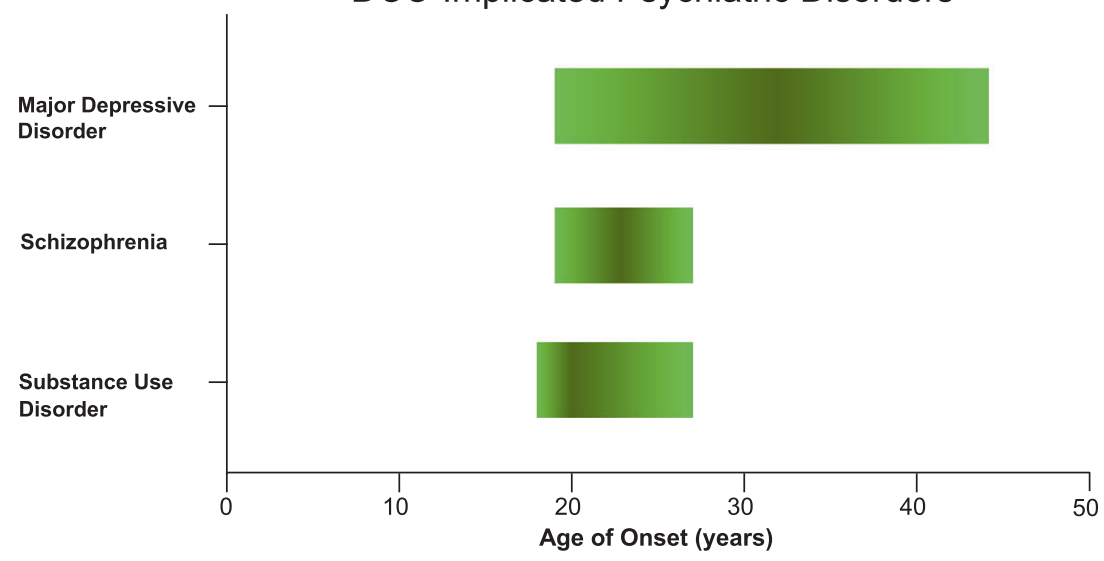

(the degree to which functional magnetic resonance imaging (fMRI) blood oxygen level-dependent (BOLD) signals from disparate brain regions are temporally correlated) are altered in the mesocorticolimbic system in schizophrenia [12], stimulant drug addiction [13, 14], and depression [15, 16], each of which begins to emerge in adolescence [17, 18]. The proposal here is that DCC-mediated Netrin-1 signaling alterations might be an important contributing factor [6, 7, 19] (Fig. 1).

\section{Axon guidance}

The axon guidance properties of Netrin-1 and its receptor, DCC, are shared by a larger class of proteins which operate according to the following general mechanisms. During neurodevelopment, axon navigation is directed by extracellular axon guidance cues, which attract or repel growing axons by inducing molecular changes in their growth cones [2]. Growth cones are versatile structures with actin-based finger-like extensions (filopodia) and protruding sheets (lamellipodia) in their peripheral domains and microtubules in their central domains. Guidance cues induce elongation, retraction, or turning of growth cones, by altering the relative rates of polymerization and depolymerization in actin filaments as well as changes in microtubule stabilization of the growth cone's cytoskeletal proteins, including actin filaments and microtubules [20]. These processes play a critical role in the organization of brain connectivity and are coordinated by a small number of guidance cue families, including the netrins, slits, semaphorins, and ephrins [2, 21]. There are many members of these families as well as splice 
variants [2, 21]. While the present review focusses on Netrin-1 and its receptor, DCC, there are additional Netrin-1 receptors including Neogenin [22], uncoordinated 5 homologues (UNC5-H) [23], and Down syndrome cell adhesion molecule (DSCAM) that contribute to the orchestration of neuronal networks [24]. Furthermore, in addition to guidance cue systems, cell adhesion molecules, such as neural cell adhesion molecules (NCAM) [25] and cadhedrins [26], as well as growth factors, also play critical roles in brain connectivity processes (i.e., synapse formation [27], axon branching [28], and axon guidance [29]).

\section{Netrin-1 and its DCC receptor}

Netrin-1 is a mammalian laminin-related diffusible molecule that interacts attractively or repulsively with several receptors, including DCC [30]. These effects of Netrin-1 play a well-documented role in axonal pathfinding, an evolutionarily conserved process demonstrated in several species, including Drosophila [31], C. elegans [32], and rodents [6]. The role of netrin and its receptors continues beyond the laying down of pathway connectivity. Indeed, once axons reach their intermediate or final targets, Netrin-1 participates in connectivity-related processes, including target recognition, axon branching, synaptogenesis, and synaptic plasticity $[11,30,32,33]$.

DCC receptors are part of the immunoglobulin superfamily and their extracellular domains are composed of four immunoglobulin domains, in addition to six fibronectin type III repeats [34]. The fourth, fifth, and sixth fibronectin type III repeats constitute the binding sites for Netrin-1 [35]. In humans and rodents, the DCC gene is located on chromosome 18 and comprises 29 exons [36]. The first demonstration of DCC's role in axon guidance was in commissural fibers of the developing neural tube [37], but DCC's role is not restricted to these fibers or to this early stage. Instead, DCC remains expressed across the lifespan throughout the nervous system [38-40]. DCC and Netrin-1 are highly expressed in dopamine cell bodies and terminal regions, including the SN, VTA, striatum, hippocampus, and cerebral cortex, in both rodents and humans [38-45].

Mice bred for $D c c$ haploinsufficiency $(+/-)$ have altered adolescent development of mesocorticolimbic dopamine neurons affecting dopamine transmission and dopamine-related behaviors in adulthood [6, 7]. Adult $\mathrm{DCc}^{+/-}$mice exhibit increased dopamine axon innervation, dopamine presynaptic sites, and amphetamine-induced dopamine release in the PFC. In comparison, in the NAcc, there are decreases in dopamine varicosities and amphetamine-induced dopamine release [8, 42, 45, 46]. The latter effects result from ectopic growth of mesolimbic dopamine axons to the PFC, a concomitant increase in mesocortical dopamine synapses [8], function [47], and augmented cortical inhibitory control over the responsiveness of mesolimbic dopamine neurons [48]. These changes are concordant with the findings that, as adults, but not as adolescents, $D c c^{+/-}$mice display multiple alterations to dopamine-related behaviors, including diminished sensitivity to the effects of stimulant drugs (cocaine, amphetamine, methamphetamine) on locomotor activity, sensorimotor gating, conditioned place preference, and intracranial selfstimulation [6, 42, 49, 50]. These behavioral effects have been observed primarily under pharmacological challenge conditions but drug-free adult DCC-deficient mice exhibit reduced impulsivity [8] and attend less to a novel object in the presence of a familiar object [51]. These altered drug responses might be specific to stimulants, given that no differences in conditioned place preference responses are observed to either morphine or ethanol between Dcc haploinsufficient mice and controls (Personal Communication; Flores, Keifer, Darq and Nouel).

Behavioral and neurochemical effects of DCC haploinsufficiency are mirrored by Netrin-1 haploinsufficiency. In adulthood, but not in adolescence, Netrin-1 haploinsufficient mice exhibit increased medial PFC (mPFC) dopamine concentrations and reduced sensitivity to the behavioral effects of amphetamine [48]. Finally, adolescent amphetamine administration alters the expression of both DCC in dopamine neurons and Netrin-1 in the NAcc and mPFC [52].

In the following sections, we collate the evidence that similar DCC and Netrin-1 related effects occur in humans, influencing susceptibility to mood disorders, psychosis, and addictions. As described above, specifically during adolescence, DCC and Netrin-1 mediate dopamine axon targeting in rodents. These processes coincide with changing levels of a microRNA which suppresses DCC expression, miR-218 [7]. In comparison, directly testing temporal effects is generally not possible in human genetic association studies, given that the polymorphisms or mutations are present throughout the lifespan. Nonetheless, as depicted in Fig. 1, the observation that the psychiatric disorders associated with DCC and Netrin-1 polymorphisms begin to emerge in adolescence raises the tantalizing possibility that the processes follow a parallel neurodevelopmental pathway.

\section{Human genetic investigations of $D C C$}

\section{Schizophrenia}

Several studies have linked $D C C$ polymorphisms with schizophrenia. In a candidate gene study, comprising 556 schizophrenia patients and 208 healthy controls, a SNP (rs2270954) in DCC was found to be nominally associated with schizophrenia. It was postulated that because this SNP 
is within the regulatory $3^{\prime}$ untranslated region (UTR), it may alter DCC mRNA stability and consequently levels of DCC protein translation [53]. Given that the $3^{\prime} \mathrm{UTR}$ region contains microRNA (miRNA) binding sequences, the identified SNP may disrupt miRNA binding, potentially increasing DCC expression by preventing DCC mRNA transcript degradation and/or translation inhibition $[54,55]$.

A second candidate gene study of 454 patients with schizophrenia and 486 healthy controls reported a nominal association with a DCC SNP (rs2229080) on exon 3 [56]. The authors also found evidence that rs2229080 induces a protein structural change and, according to in silico analyses, alters splicing regulation. Moreover, the authors noted that rs2229080 is a known target of loss of heterozygosity (LOH) and that such $\mathrm{LOH}$ is associated with reduced DCC expression [57]. Thus, if the rs2229080 risk allele disrupts the LOH target site (which downregulates DCC), the authors proposed that the risk allele would result in increased DCC expression, changing mesocorticolimbic dopamine development and ultimately contributing to the schizophrenia phenotype [56]. Subsequently, a much larger genome wide association study (GWAS), applying a false discovery rate (FDR) correction, found that an intronic locus of $D C C$ (rs4632195) is associated with schizophrenia $(n=82,315)$ [58]. A mechanism regarding predicted expression outcomes remains to be determined for this SNP. Most recently, by applying next-generation sequencing, which sequences the entire genome and can detect rare variants, loci in five genes, including $D C C$, were shared among three family members exhibiting atypical psychosis [59].

\section{Depression}

Over the past six years, there has been rapidly accumulating evidence that both genetic variants and other factors that alter $D C C$ expression also affect susceptibility to mood dysregulation and suicide. Two independent studies from our group, in a discovery and replication cohort, have demonstrated that depressed suicide completers exhibit elevated DCC mRNA expression in the PFC, and a corresponding downregulation of the DCC miRNA repressor, miR-218 [54, 60]. Moreover, a genome-wide investigation of differential gene expression in blood, applying a Bayesian approach, identified 165 differentially expressed genes in major depressive disorder, including overexpression of DCC [61]. Further strengthening these findings is a bloodderived methylome-wide association study (MWAS) of 812 patients with depression and 320 controls, which found associations between methylation sites in DCC and depression [62]. Notably, while there is evidence of general concordance between DNA methylation across blood and brain tissue, there are exceptions [63], and this is a limitation of the study.
GWAS research has identified an intronic DCC SNP (rs4542757) associated with depressive symptoms $(n=$ 3138) [64]. Although this effect did not achieve genomewide significance and was not identified in a replication sample, the GWAS study was likely underpowered [64]. A larger GWAS study $(n=161,460)$ identified an association between depressive symptoms and an intronic DCC SNP, rs62100776 [65]. Moreover, using pathway analyses in two independent samples $(n=6455, \quad n=18,759)$, FDRcorrected associations between depression and a Netrin-1 signaling pathway were identified, comprising SNPs from multiple genes involved in Netrin-1 signaling, including DCC [66]. Additionally, gene-based tests found that depressive symptoms among participants in the UK Biobank $(n=99,057)$ were associated with six genes, including $D C C$ [67]. Another UK Biobank $(n=122,935)$ gene-based analysis found associations between suicidality and five genes, including DCC [68]. Finally, a GWAS meta-analysis of 135,458 individuals with major depression and 344,901 controls identified 44 genomic loci significantly associated with depression, including an intronic DCC SNP (rs11663393) [69].

The above associations might reflect an effect on mood instability, a clinical feature common to numerous psychiatric disorders [70]. In a GWAS study of 60,443 controls and 53,525 mood instability cases, genome-wide significance was detected for four independent genetic loci, including an intronic DCC SNP (rs8084280) [71]. In line with this idea, genetic correlations, which assess the degree of shared heritability between phenotypes, were identified between mood instability and three psychiatric conditions: major depressive disorder, schizophrenia, and anxiety disorder [71].

Recently, a UK Biobank study $(n=\sim 6400)$ found that the SNPs in the Netrin-1 signaling pathway conferring risk for major depression are associated with altered white matter microstructure in thalamic radiations, namely lower fractional anisotropy and higher mean diffusivity [72].

Strikingly, a UK Biobank meta-GWAS $(n=375,275)$ identified an association between anhedonia and a locus in $D C C$, which was the most statistically significant finding [73]. The authors also reported high genetic correlations between anhedonia and depression, as well as a moderate genetic correlation with schizophrenia [73]. Moreover, a higher anhedonia polygenic score predicted reduced brain volumes, including in the NAcc and mPFC, as well as altered white matter integrity in multiple pathways [73].

Furthermore, a genome-wide methylation study of 150 pairs of monozygotic twins (one co-twin with, and one without, early onset major depression), identified altered methylation in Netrin-1, among other genes in depression [74]. An additional meta-GWAS study reported that a Netrin-1 SNP, rs8081460, was associated with neuroticism 
(which is highly genetically correlated with depression) in the UK Biobank sample $(n=91,370)$, although this SNP effect did not replicate in two smaller, independent samples ( $n=6659$ and $n=8687$ ) [75].

The larger number of studies implicating DCC, relative to Netrin-1, variants is notable. We propose that changes in receptor expression/function, including DCC, result in modifications in Netrin-1's actions (attracting or repelling). Therefore, subtle spatiotemporal variation in DCC expression could be sufficient to produce changes in connectivity, even if total Netrin-1 expression is unaltered [6].

In the largest cross-disorder meta-GWAS of neuropsychiatric disorders to date, comprising more than 232,964 cases and 494,162 controls across eight disorders, the intronic DCC SNP, rs8084351, had the most robust pleiotropic effects [76]. This striking finding indicates that the effects of DCC and Netrin-1 are important across a wide variety of psychiatric disorders.

\section{DCC haploinsufficiency: personality traits and drug- related behaviors}

While GWAS studies typically detect relatively subtle effects of DCC polymorphisms [77], loss-of-function haploinsufficient $D C C$ mutation carriers were expected to exhibit larger effects, detectable with smaller sample sizes. Our group recently conducted neuroimaging and psychological studies of a large Quebec family $(n=36)$, half of whom possess a heterozygous frameshift mutation to $D C C$ (NM_005215.3, c. $1140+1 \mathrm{G}>\mathrm{A}$ ). The resulting mutated allele encodes a truncated DCC protein that fails to bind to Netrin-1 [78]. As in Dcc haploinsufficient mice, robust anatomical and behavioral phenotypes are observed as a consequence of human DCC haploinsufficiency, underscoring the sensitivity of the system. The $D C C$ haploinsufficient Quebecers have an adult behavioral phenotype that shares two striking features with adult Dcc haploinsufficient mice [79]. First, the adult DCC haploinsufficient humans exhibit reduced novelty seeking personality traits [79]. Second, compared with their unaffected relatives, the $D C C$ haploinsufficient humans smoke less tobacco yet use similar amounts of alcohol and cannabis [79], consistent with the evidence in mice that DCC's effects are specific to stimulant drugs. Notably, cigarette smoking increases dopamine transmission in humans [80] while lowered dopaminergic tone can decrease smoking [81], indicating that an altered smoking phenotype could reflect alterations to the dopamine system.

These findings are bolstered by a large meta-GWAS $(n=518,633)$, which identified associations between an intronic DCC SNP, rs1221976, and self-reported "ever smoker" [82]. This finding was part of a larger study on risk-tolerance, whereby $D C C$ SNPs were also associated with "adventurousness", defined as the propensity to be "adventurous versus cautious." An additional UK Biobank GWAS study $(n \sim 458,000)$ identified an intronic $D C C$ SNP, rs12970816, associated with cigarette smoking status [83]. Finally, one more study (discovery: $n=5339$, replication: $n=1682$ ) reported that the intronic DCC SNP, rs1372626, while not genome-wide significant, was the SNP most strongly associated with cigarette smoking, and was plausibly underpowered [84].

Moreover, in a human multivariate investigation, using a powerful and sensitive alternative to traditional SNP studies, $D C C$ was among the top genes associated with impulsivity $(n=426)$ [85]. Since diminished novelty seeking is associated with reduced dopamine release in the ventral striatum of humans and rodents [14, 86, 87] these behavioral alterations might reflect DCC's effects on mesocorticolimbic dopamine development and striatal dopamine transmission [42].

\section{DCC haploinsufficiency: dopamine mesocorticolimbic connectivity}

The associations between $D C C$ and psychiatric disorders might be a consequence of $D C C$-related alterations to mesocorticolimbic pathways. As predicted, our group revealed that DCC haploinsufficient members of the Quebec family, as compared with control groups without the mutation (i.e., both relatives and unrelated healthy volunteers) exhibit striking reductions in anatomical connectivity, assessed using diffusion MRI probabilistic tractography, from the SN/VTA to both the ventral striatum and ventral mPFC [79].

These effects might include changes to dopamine pathways, but some caution is warranted. First, the reduced mesocortical connectivity differs from the increased cortical dopamine innervation seen in adult $D c c$ haploinsufficient mice. Second, MRI methodologies do not discern the underlying neurochemistry. Indeed, since mesocorticolimbic pathways contain dopamine, gamma-aminobutyric acid (GABA) and glutamate axons [88], the anatomical connectivity findings in humans plausibly represent alterations to both dopaminergic and non-dopaminergic axons. These same considerations also raise the possibility that the dopamine focused studies in rodents have yet to identify alterations to inter-connected non-dopamine neurons.

In rodents, there is a complementary receptor to ligand expression pattern of DCC and Netrin-1 in the NAcc and PFC. While dopamine axons express high DCC levels in the NAcc, they only rarely express DCC in the PFC [45]. Conversely, the intensity of Netrin-1 expression in the NAcc is low, especially compared to the PFC, where Netrin-1 expression is substantial [45]. Indeed, dopamine axons expressing high levels of DCC target the NAcc and do not continue to grow to the PFC in adolescence [8]. In 
the case of $D c c$ haploinsufficiency, since DCC expression is reduced, mesolimbic dopamine axons fail to recognize the NAcc as their final target and instead continue to grow ectopically into the PFC throughout adolescence [8]. In human $D C C$ mutation carriers with reduced mesocortical anatomical connectivity, these same effects might be occurring yet the larger distances to be covered might lead the misrouted mesocortical axons to disperse more diffusely, compared to the rodents.

\section{Striatal brain volume}

We recently reported that both $D C C$ haploinsufficient humans and mice exhibit reduced striatal volumes. While these effects occur in the NAcc in mice, they are localized to the putamen in humans [79]. These effects were also identified in largescale GWAS investigations. One of these GWAS studies $(n=30,717)$, part of the Enhancing Neuro Imaging Genetics through Meta-Analysis (ENIGMA) initiative, investigated genetic variants associated with the volumes of subcortical structures [89]. Putamen volume was associated with four genetic loci, including an intronic DCC SNP (rs62097986), in both discovery and replication cohorts [89].

Bilateral putamen volume has also been associated with an intronic SNP in DCC (rs62098013), as identified in the UK Biobank Brain Imaging Data browser (http://big.stats. ox.ac.uk/), which comprises neuroimaging GWAS data from 9,707 participants [90]. Confidence in this finding is bolstered by a more recent GWAS study that reported an additional intronic locus of DCC (rs4632195) associated with both putamen volume $(n=11,598)$ and schizophrenia $(n=82,315)$ [58]. The risk allele for schizophrenia is associated with larger putamen volumes.

Earlier work also identified larger putamen volumes among those with schizophrenia [91], consistent with the two genetic investigations that found associations between SNPs in $D C C$ and schizophrenia $[53,56]$. This observation fits well with our earlier proposal that schizophrenia is associated with increased $D C C$ expression [53]. Moreover, in discovery $(n=905)$ and replication $(n=166)$ cohorts, variants in genes incurring risk for schizophrenia, including $D C C$, were associated with alterations in gray matter volumes (putamen, thalamus, temporal gyrus), resting state functional magnetic resonance imaging (rs-fMRI) signals in the mPFC, and working-memory performance [92].

These striatal volumetric effects might have implications for mood disorders as well. In depression, there are reports of decreased putamen volume [93-95], although some other groups have failed to replicate this finding [96] potentially reflecting small sample sizes, heterogeneity within the diagnostic category, and medication effects. Indeed, there is recent MRI evidence that, in psychotropic medication-naïve participants $(n=625)$, elevated putamen gray matter volume is a disease risk marker across multiple diagnostic categories, namely schizophrenia, major depression, obsessive compulsive disorder, and post-traumatic stress disorder [97].

\section{Cortical volume}

The DCC haploinsufficient Quebecers also demonstrate modest volumetric increases in two cortical regions: the $\mathrm{mPFC} /$ anterior cingulate cortex and the ventral mPFC [79]. In comparison, among human carriers of another DCC mutation, a completely different phenotype is observed, such that there is a complete absence of the cingulate gyrus [98]. Volumetric cortical changes are not observed in Dcc haploinsufficient mice [79] and have not been identified in human neuroimaging GWAS investigations, to the authors' knowledge, and therefore, the cortical findings may have limited generalizability.

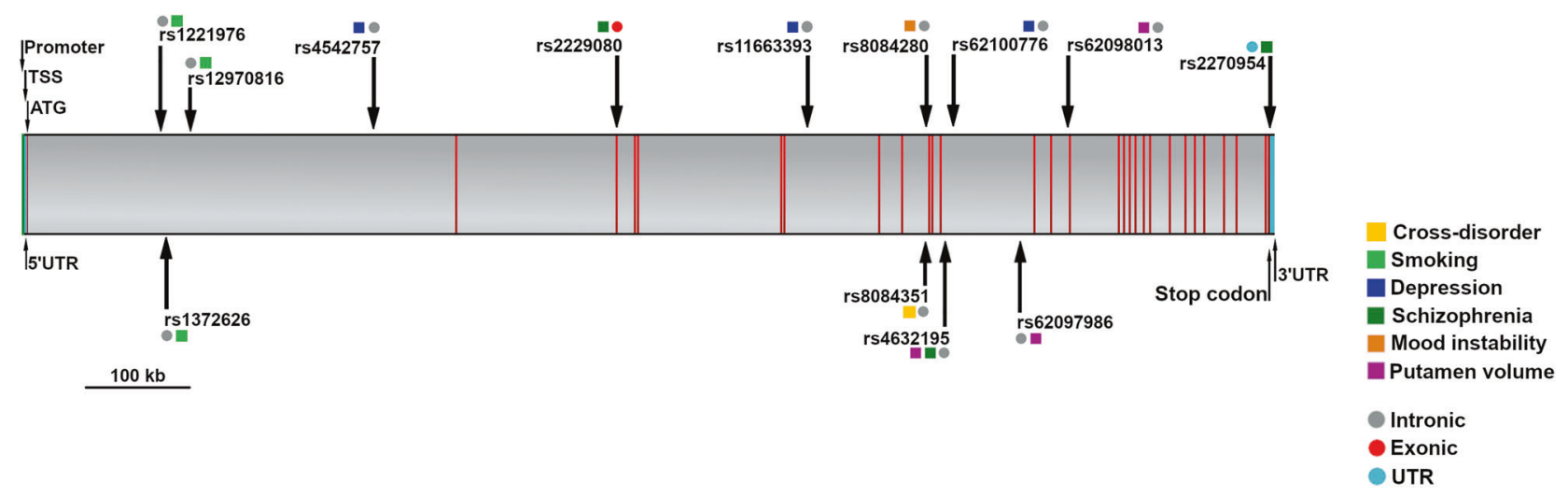

Fig. 2 Single nucleotide polymorphisms (SNPs) and associated phenotypes in the $D C C$ gene. Depicted here is the $5^{\prime}-3^{\prime}$ oriented $D C C$ gene, comprising 29 exons (red), intervening introns (gray), untranslated regions (UTR; teal), transcriptional start site (TSS) region, promoter region, start codon (ATG) and stop codon. The rs ID for each SNP and associated phenotype(s) are indicated. The phenotypes are cross disorder (yellow), smoking (light green), depression (blue), schizophrenia (dark green), mood instability (orange), and putamen volume (purple). The gene structure and SNP locations were determined using the NCBI tool, Variation Viewer (https://www.ncbi.nlm. nih.gov/variation/view/), using the genome assembly, GRCh38.p12 


\section{Identification of different DCC SNPs}

The effects reported here are related to multiple SNPs (Fig. 2). This could reflect several factors, including linkage disequilibrium, the set of SNPs examined, the genetic compositions of samples, the statistical procedures, the sample sizes (i.e., statistical power), and the differing use of covariates. Of note, $85 \%$ of the discussed DCC SNPs are intronic, indicating that they plausibly influence splicing, and consequently, DCC mRNA transcription and translation; [99] such intronic SNPs may affect enhancers or repressors which may distally regulate $D C C$ transcription [100].

\section{Conclusions}

This review highlights accumulating evidence that Netrin1 and its receptor DCC contribute to mesocorticolimbic dopamine related psychiatric disorders that emerge during adolescence (Tables 1 and 2). The findings are strikingly convergent across heterogenous methodologies and

Table 1 Summary of human genetic studies of DCC and Netrin-1

\begin{tabular}{|c|c|c|c|c|c|}
\hline References & Genetic approach & Gene & Sample size & Ancestry & Phenotype \\
\hline \multicolumn{6}{|l|}{ Mood disorders } \\
\hline Manitt et al. [60] & mRNA expression & DCC mRNA & 30 cases, 35 controls & Not available & Depressed suicide completers \\
\hline Dunn et al. [64] & Genome-wide association study (GWAS) & $D C C$ gene & 3138 & Hispanic & Depression \\
\hline Okbay et al. [65] & GWAS & $D C C$ gene & 161,460 & European & Depression \\
\hline Smith et al. [75] & Meta-GWAS & Netrin-1 & $\begin{array}{l}91,370 \text {, replication } \\
\text { samples: }(6659,8687)\end{array}$ & White, United Kingdom & Neuroticism \\
\hline Torres-Berrío et al. [54] & mRNA expression & $D C C m R N A$ & 11 cases, 12 controls & Not available & Depressed suicide completers \\
\hline Zeng et al. [66] & $\begin{array}{l}\text { Pathway analysis, multilevel regional } \\
\text { heritability, and polygenic risk score }\end{array}$ & $\begin{array}{l}\text { Netrin-1 signaling } \\
\text { pathway }\end{array}$ & 25,214 & European & Depression \\
\hline Aberg et al. [62] & $\begin{array}{l}\text { Methylome-wide association } \\
\text { study (MWAS) }\end{array}$ & $D C C$ methylation sites & 812 cases, 320 controls & European & Depression \\
\hline Leday et al. [61] & Genome-wide gene expression & $D C C m R N A$ & 207 cases, 157 controls & Caucasion & Depression \\
\hline Roberson-Nay et al. [74] & Genome-wide methylation study & Netrin-I & $\begin{array}{l}150 \text { monozygotic } \\
\text { twin pairs }\end{array}$ & Caucasion & Depression \\
\hline Wray et al. [69] & GWAS & $D C C$ gene & $\begin{array}{l}135,458 \text { cases, } 344,901 \\
\text { controls }\end{array}$ & European & Depression \\
\hline Arnau-Soler et al. [67] & Gene-based test & $D C C$ gene & 99,057 & White, United Kingdom & Depression \\
\hline Barbu et al. [72] & Polygenic risk score & $\begin{array}{l}\text { Netrin-1 signaling } \\
\text { pathway }\end{array}$ & $\sim 6400$ & Not available & Depression \\
\hline Lee et al. [76] & Meta-GWAS & $D C C$ gene & $\begin{array}{l}232,964 \text { cases, } 494,162 \\
\text { controls }\end{array}$ & European & Cross-disorder \\
\hline Strawbridge et al. [69] & Gene-based test & $D C C$ gene & 122,935 & White, United Kingdom & Suicidality \\
\hline Ward et al. [73] & $\begin{array}{l}\text { Meta-GWAS, polygenic score, genetic } \\
\text { correlations }\end{array}$ & $D C C$ gene & 375,275 & European & Anhedonia \\
\hline \multicolumn{6}{|c|}{ Personality traits and substance use } \\
\hline Khadka et al. [85] & Parallel independent component analysis & $D C C$ gene & 426 & $\begin{array}{l}\text { Caucasion, African- } \\
\text { American, Hispanic, other }\end{array}$ & Impulsivity \\
\hline Zanetti et al. [84] & GWAS & $D C C$ gene & 5339, replication: 1662 & African-American & Cigarette smoking \\
\hline Ward et al. [71] & GWAS & $D C C$ gene & $\begin{array}{l}53,525 \text { cases, } 60,443 \\
\text { controls }\end{array}$ & White, United Kingdom & Mood Instability \\
\hline Vosberg et al. [79] & Rare mutation cohort & $D C C$ gene & 20 cases, 36 controls & $\begin{array}{l}\text { Caucasion French } \\
\text { Canadian (cases) }\end{array}$ & Novelty seeking \& tobacco use \\
\hline Kichaev et al. [83] & GWAS & $D C C$ gene & $n \sim 458,000$ & European & Cigarette smoking \\
\hline Lee et al. [76] & Meta-GWAS & $D C C$ gene & $\begin{array}{l}232,964 \text { cases, } 494,162 \\
\text { controls }\end{array}$ & European & Cross-disorder \\
\hline Linnér et al. [82] & Meta-GWAS & $D C C$ gene & $n=518,633$ & European & Cigarette smoking \\
\hline \multicolumn{6}{|c|}{ Schizophrenia and psychosis } \\
\hline Grant et al. [53] & Candidate gene & $D C C$ gene & 556 cases, 208 controls & $\begin{array}{l}\text { African American, Asian, } \\
\text { Caucasion }\end{array}$ & Schizophrenia \\
\hline Yan et al. [56] & Candidate gene & $D C C$ gene & 454 cases, 486 controls & Han Chinese & Schizophrenia \\
\hline Okayama et al. [59] & Next-generation sequencing & $D C C$ gene & 3 cases & Japanese & Atypical psychosis \\
\hline Smeland et al. [58] & GWAS & $D C C$ gene & 82,315 & European, East Asian & Schizophrenia \\
\hline Lee et al. [76] & Meta-GWAS & $D C C$ gene & $\begin{array}{l}232,964 \text { cases, } 494,162 \\
\text { controls }\end{array}$ & European & Cross-disorder \\
\hline \multicolumn{6}{|l|}{ Neurobiology } \\
\hline Hibar et al. [89] & GWAS & $D C C$ gene & 30,717 & European & Putamen Volume \\
\hline Elliot et al. [90] & GWAS & $D C C$ gene & 9707 & White, United Kingdom & Putamen Volume \\
\hline Luo et al. [92] & Polygenic risk score & $\begin{array}{l}\text { Schizophrenia-associated } \\
\text { genes including } D C C\end{array}$ & $\begin{array}{l}\text { Discovery }(n=905) \\
\text { replication }(n=166)\end{array}$ & Han Chinese & $\begin{array}{l}\text { Putamen, thalamus, temporal gyrus volumes; } \\
\text { mPFC rs-fMRI activity; working-memory }\end{array}$ \\
\hline Smeland et al. [58] & GWAS & $D C C$ gene & 11,598 & European & Putamen volume \\
\hline Vosberg et al. [79] & Rare mutation cohort & $D C C$ gene & 20 cases, 36 controls & $\begin{array}{l}\text { Caucasion French } \\
\text { Canadian (cases) }\end{array}$ & $\begin{array}{l}\text { Mesocorticolimbic anatomical connectivity \& } \\
\text { putamen volume }\end{array}$ \\
\hline Barbu et al. [72] & Polygenic risk score & $\begin{array}{l}\text { Netrin-1 signaling } \\
\text { pathway }\end{array}$ & $\sim 6400$ & Not available & Thalamic raditions, white matter integrity \\
\hline
\end{tabular}


Table 2 Summary of DCC and Netrin-1 effects across brain regions

\begin{tabular}{llll}
\hline Brain region & Measure & Mice & Humans \\
\hline Striatum & A. Expression & High DCC, low Netrin-1 & $\begin{array}{l}\text { Both Netrin-1 and DCC are expressed and their expression decreases } \\
\text { across the lifespan }\end{array}$ \\
& B. Volume & Reduced in ventral striatum & $\begin{array}{l}\text { Reduced in dorsal striatum } \\
\text { Reduced mesolimbic anatomical connectivity }\end{array}$ \\
& C. Connectivity & $\begin{array}{l}\text { Reduced mesolimbic dopamine } \\
\text { innervation }\end{array}$ & Higher DCC than Netrin-1 (prenatally) \\
Cortex & A. Expression & Low DCC, high Netrin-1 (mPFC) & Reduced \\
& B. Volume & No difference & Reduced mesocortical anatomical connectivity \\
& C. Connectivity & $\begin{array}{l}\text { Increased mesocortical dopamine } \\
\text { innervation }\end{array}$ & \\
\hline
\end{tabular}

(A) DCC and Netrin-1 relative expression levels in wild-type mice [7] and humans [39] (See also: http://development.psychencode.org). Group differences in (B) volumes and (C) connectivity in DCC haploinsufficient mice [7] and humans [79], relative to control groups

samples and both between and within studies in humans and mice.

Acknowledgements CF is supported by the National Institute on Drug Abuse (R01DA037911), the Natural Science and Engineering Research Council of Canada (2982226), and Canadian Institutes of Health Research (MOP-74709, 119543). ML is supported by three grants from the Canadian Institutes of Health Research (MOP-119543, 133537, 152910). DEV received scholarship support from Le Fonds de recherche du Québec - Santé (FRQS) and McGill University Faculty of Medicine Internal Studentship Awards (the Hugh E. Burke Fellowship and the James O. and Maria Meadows Fellowship). We would like to acknowledge Drs. Tomáš Paus and Patricia Pelufo Silveira for their feedback on an earlier version of the manuscript and Drs. Alanna Grant and Lauren Reynolds for their advice on figure preparation.

Author contributions DEV, ML, and CF all contributed to the writing, literature search, and conception of the figures. DEV generated the figures.

\section{Compliance with ethical standards}

Conflict of interest The authors declare that they have no conflict of interest.

Publisher's note Springer Nature remains neutral with regard to jurisdictional claims in published maps and institutional affiliations.

Open Access This article is licensed under a Creative Commons Attribution 4.0 International License, which permits use, sharing, adaptation, distribution and reproduction in any medium or format, as long as you give appropriate credit to the original author(s) and the source, provide a link to the Creative Commons license, and indicate if changes were made. The images or other third party material in this article are included in the article's Creative Commons license, unless indicated otherwise in a credit line to the material. If material is not included in the article's Creative Commons license and your intended use is not permitted by statutory regulation or exceeds the permitted use, you will need to obtain permission directly from the copyright holder. To view a copy of this license, visit http://creativecommons. org/licenses/by/4.0/.

\section{References}

1. Murre JMJ, Sturdy DPF. The connectivity of the brain: multilevel quantitative analysis. Biol Cyber. 1995;73:529-45.

2. Dickson BJ. Molecular mechanisms of axon guidance. Science. 2002;298:1959-64.

3. Haber SN, Knutson B. The Reward Circuit: Linking Primate Anatomy and Human Imaging. Neuropsychopharmacology. 2010;35:4-26.

4. Sesack SR, Grace AA. Cortico-basal ganglia reward network: microcircuitry. Neuropsychopharmacology. 2010;35:27-47.

5. Yetnikoff L, Lavezzi HN, Reichard RA, Zahm DS. An update on the connections of the ventral mesencephalic dopaminergic complex. Neuroscience. 2014;282:23-48.

6. Flores $\mathrm{C}$. Role of netrin-1 in the organization and function of the mesocorticolimbic dopamine system. J Psychiatry Neurosci. 2011;36:296-310.

7. Hoops D, Flores C. Making Dopamine Connections in Adolescence. Trends Neurosci. 2017;40:709-19.

8. Reynolds LM, Pokinko M, Berrío AT, Cuesta S, Lambert LC, Pellitero EDC, et al. DCC receptors drive prefrontal cortex maturation by determining dopamine axon targeting in adolescence. Biol Psychiatry. 2018;83:181-92.

9. Düzel E, Bunzeck N, Guitart-Masip M, Wittmann B, Schott BH, Tobler PN. Functional imaging of the human dopaminergic midbrain. Trends Neurosci. 2009;32:321-8.

10. Lewis DA, Melchitzky DS, Sesack SR, Whitehead RE, Auh S, Sampson A. Dopamine transporter immunoreactivity in monkey cerebral cortex: regional, laminar, and ultrastructural localization. J Comp Neurol. 2001;432:119-36.

11. Taber KH, Black DN, Porrino LJ, Hurley RA. Neuroanatomy of dopamine: reward and addiction. J Neuropsychiatry Clin Neurosci. 2012;24:1-4.

12. Horga G, Cassidy CM, Xu X, Moore H, Slifstein M, Van Snellenberg JX, et al. Dopamine-related disruption of functional topography of striatal connections in unmedicated patients with schizophrenia. JAMA psychiatry. 2016;73:862-70.

13. Kohno M, Morales AM, Ghahremani DG, Hellemann G, London ED. Risky decision making, prefrontal cortex, and mesocorticolimbic functional connectivity in methamphetamine dependence. JAMA Psychiatry. 2014;71:812-20.

14. Leyton M, Vezina P. Dopamine ups and downs in vulnerability to addictions: a neurodevelopmental model. Trends Pharm Sci. 2014;35:268-76. 
15. Furman DJ, Hamilton JP, Gotlib IH. Frontostriatal functional connectivity in major depressive disorder. Biol mood anxiety Disord. 2011;1:1-11.

16. Russo SJ, Nestler EJ. The brain reward circuitry in mood disorders. Nat Rev Neurosci. 2013;14:609-25.

17. Kessler RC, Berglund P, Demler O, Jin R, Merikangas KR, Walters EE. Lifetime prevalence and age-of-onset distributions of DSM-IV disorders in the National Comorbidity Survey Replication. Arch Gen Psychiatry. 2005;62:593-602.

18. Kessler RC, Amminger GP, Aguilar-Gaxiola S, Alonso J, Lee S, Ustun TB. Age of onset of mental disorders: a review of recent literature. Curr Opin Psychiatry. 2007;20:359-64.

19. Reynolds LM, Flores C. Guidance cues: linking drug use in adolescence with psychiatric disorders. Neuropsychopharmacology. 2019;44:225-6.

20. Dent EW, Gupton SL, Gertler FB. The Growth Cone Cytoskeleton in Axon Outgrowth and Guidance. Cold Spring Harb Perspect Biol. 2011;3:a001800.

21. Van Battum EY, Brignani S, Pasterkamp RJ. Axon guidance proteins in neurological disorders. Lancet Neurol. 2015;14: 532-46.

22. Mawdsley DJ, Cooper HM, Hogan BM, Cody SH, Lieschke GJ, Heath JK. The Netrin receptor Neogenin is required for neural tube formation and somitogenesis in zebrafish. Dev Biol. 2004;269:302-15.

23. Finci LI, Krüger N, Sun X, Zhang J, Chegkazi M, Wu Y, et al. The crystal structure of netrin- 1 in complex with DCC reveals the bifunctionality of netrin-1 as a guidance cue. Neuron. 2014;83:839-49.

24. Ly A, Nikolaev A, Suresh G, Zheng Y, Tessier-Lavigne M, Stein E. DSCAM is a netrin receptor that collaborates with DCC in mediating turning responses to netrin-1. Cell. 2008;133: 1241-54.

25. Brennaman LH, Maness PF. Developmental regulation of GABAergic interneuron branching and synaptic development in the prefrontal cortex by soluble neural cell adhesion molecule. Mol Cell Neurosci. 2008;37:781-93.

26. Barnes SH, Price SR, Wentzel C, Guthrie SC. Cadherin-7 and cadherin-6B differentially regulate the growth, branching and guidance of cranial motor axons. Development. 2010;137: 805-14.

27. Schmeisser MJ, Baumann B, Johannsen S, Vindedal GF, Jensen $\mathrm{V}$, Hvalby $\varnothing \mathrm{C}$, et al. IкB kinase/nuclear factor $\kappa \mathrm{B}$-dependent insulin-like growth factor 2 (Igf2) expression regulates synapse formation and spine maturation via Igf2 receptor signaling. J Neurosci. 2012;32:5688-703.

28. Szebenyi G, Dent EW, Callaway JL, Seys C, Lueth H, Kalil K. Fibroblast growth factor-2 promotes axon branching of cortical neurons by influencing morphology and behavior of the primary growth cone. J Neurosci. 2001;21:3932-41.

29. Ebens A, Brose K, Leonardo ED, Hanson MG Jr, Bladt F, Birchmeier C, et al. Hepatocyte growth factor/scatter factor is an axonal chemoattractant and a neurotrophic factor for spinal motor neurons. Neuron. 1996;17:1157-72.

30. Boyer NP, Gupton SL. Revisiting Netrin-1: one who guides (axons). Front Cell Neurosci. 2018;12:1-18.

31. Brankatschk M, Dickson BJ. Netrins guide Drosophila commissural axons at short range. Nat Neurosci. 2006;9:188-94.

32. Teichmann HM, Shen K. UNC-6 and UNC-40 promote dendritic growth through PAR-4 in Caenorhabditis elegans neurons. Nat Neurosci. 2011;14:165-72.

33. Glasgow SD, Labrecque S, Beamish IV, Aufmkolk S, Gibon J, Han D, et al. Activity-Dependent Netrin-1 Secretion Drives Synaptic Insertion of GluA1-Containing AMPA Receptors in the Hippocampus. Cell Rep. 2018;25:168-182 e166.
34. Hedrick L, Cho KR, Fearon ER, Wu T-C, Kinzler KW, Vogelstein B. The DCC gene product in cellular differentiation and colorectal tumorigenesis. Genes Dev. 1994;8:1174-83.

35. Finci LI, Krüger N, Sun X, Zhang J, Chegkazi M, Wu Y, et al. The crystal structure of netrin-1 in complex with DCC reveals the bi-functionality of netrin-1 as a guidance cue. Neuron. 2014;83:839-49.

36. Cho KR, Oliner JD, Simons JW, Hedrick L, Fearon ER, Preisinger AC, et al. The DCC gene: structural analysis and mutations in colorectal carcinomas. Genomics. 1994;19:525-31.

37. Keino-Masu K, Masu M, Hinck L, Leonardo ED, Chan SS, Culotti JG, et al. Deleted in Colorectal Cancer (DCC) encodes a netrin receptor. Cell. 1996;87:175-85.

38. Gad JM, Keeling SL, Wilks AF, Tan S-S, Cooper HM. The expression patterns of guidance receptors, DCC and Neogenin, are spatially and temporally distinct throughout mouse embryogenesis. Dev Biol. 1997;192:258-73.

39. Harter P, Bunz B, Dietz K, Hoffmann K, Meyermann R, Mittelbronn M. Spatio-temporal deleted in colorectal cancer (DCC) and netrin-1 expression in human foetal brain development. Neuropathol Appl Neurobiol. 2010;36:623-35.

40. Livesey F, Hunt S. Netrin and netrin receptor expression in the embryonic mammalian nervous system suggests roles in retinal, striatal, nigral, and cerebellar development. Mol Cell Neurosci. 1997;8:417-29.

41. Osborne P, Halliday G, Cooper H, Keast J. Localization of immunoreactivity for deleted in colorectal cancer (DCC), the receptor for the guidance factor netrin-1, in ventral tier dopamine projection pathways in adult rodents. Neuroscience. 2005;131: 671-81.

42. Grant A, Hoops D, Labelle-Dumais C, Prévost M, Rajabi H, Kolb B, et al. Netrin-1 receptor-deficient mice show enhanced mesocortical dopamine transmission and blunted behavioural responses to amphetamine. Eur J Neurosci. 2007;26:3215-28.

43. Manitt C, Labelle-Dumais C, Eng C, Grant A, Mimee A, Stroh $\mathrm{T}$, et al. Peri-pubertal emergence of UNC-5 homologue expression by dopamine neurons in rodents. PLoS ONE. 2010;5: e11463.

44. Reyes S, Fu Y, Double KL, Cottam V, Thompson LH, Kirik D, et al. Trophic factors differentiate dopamine neurons vulnerable to Parkinson's disease. Neurobiol Aging. 2013;34:873-86.

45. Manitt C, Mimee A, Eng C, Pokinko M, Stroh T, Cooper HM, et al. The netrin receptor DCC is required in the pubertal organization of mesocortical dopamine circuitry. J Neurosci. 2011;31:8381-94.

46. Flores C, Manitt C, Rodaros D, Thompson K, Rajabi H, Luk K, et al. Netrin receptor deficient mice exhibit functional reorganization of dopaminergic systems and do not sensitize to amphetamine. Mol Psychiatry. 2005;10:606-12.

47. Reynolds LM, Yetnikoff L, Pokinko M, Wodzinski M, Epelbaum JG, Lambert LC, et al. Early Adolescence is a Critical Period for the Maturation of Inhibitory Behavior. Cerebral Cortex. 2018;29:1-11.

48. Pokinko M, Moquin L, Torres-Berrío A, Gratton A, Flores C. Resilience to amphetamine in mouse models of netrin-1 haploinsufficiency: role of mesocortical dopamine. Psychopharmacology. 2015;232:3719-29.

49. Kim JH, Lavan D, Chen N, Flores C, Cooper H, Lawrence AJ. Netrin-1 receptor-deficient mice show age-specific impairment in drug-induced locomotor hyperactivity but still self-administer methamphetamine. Psychopharmacology. 2013;230:607-16.

50. Reynolds LM, Gifuni AJ, McCrea ET, Shizgal P, Flores C. dcc haploinsufficiency results in blunted sensitivity to cocaine enhancement of reward seeking. Behav Brain Res. 2016;298: $27-31$. 
51. Horn KE, Glasgow SD, Gobert D, Bull S-J, Luk T, Girgis J, et al. DCC expression by neurons regulates synaptic plasticity in the adult brain. Cell Rep. 2013;3:173-85.

52. Cuesta S, Restrepo-Lozano JM, Popescu C, He S, Reynolds LM, Israel $\mathrm{S}$ et al. DCC-related developmental effects of abusedversus therapeutic-like amphetamine doses in adolescence. Addiction Biol. 2019:e12791.

53. Grant A, Fathalli F, Rouleau G, Joober R, Flores C. Association between schizophrenia and genetic variation in DCC: a case-control study. Schizophr Res. 2012;137:26-31.

54. Torres-Berrío A, Lopez JP, Bagot RC, Nouel D, Dal Bo G, Cuesta S, et al. DCC confers susceptibility to depression-like behaviors in humans and mice and is regulated by miR-218. Biol Psychiatry. 2017;81:306-15.

55. Lewis BP, Shih I-h, Jones-Rhoades MW, Bartel DP, Burge CB. Prediction of mammalian microRNA targets. Cell. 2003;115: 787-98.

56. Yan P, Qiao X, Wu H, Yin F, Zhang J, Ji Y, et al. An association study between genetic polymorphisms in functional regions of five genes and the risk of Schizophrenia. J Mol Neurosci. 2016;59:366-75.

57. Schmitt C, Thaler K, Wittig B, Kaulen H, zum Büschenfelde KM, Dippold W. Detection of the DCC gene product in normal and malignant colorectal tissues and its relation to a codon 201 mutation. Br J Cancer. 1998;77:588-94.

58. Smeland OB, Wang Y, Frei O, Li W, Hibar DP, Franke B, et al. Genetic overlap between schizophrenia and volumes of hippocampus, putamen, and intracranial volume indicates shared molecular genetic mechanisms. Schizophr Bull. 2018;44: 854-64.

59. Okayama T, Hashiguchi Y, Kikuyama H, Yoneda H, Kanazawa T. Next-generation sequencing analysis of multiplex families with atypical psychosis. Transl Psychiatry. 2018;8:1-7.

60. Manitt C, Eng C, Pokinko M, Ryan R, Torres-Berrio A, Lopez J, et al. DCC orchestrates the development of the prefrontal cortex during adolescence and is altered in psychiatric patients. Transl Psychiatry. 2013;3:1-13.

61. Leday GG, Vértes PE, Richardson S, Greene JR, Regan T, Khan $\mathrm{S}$, et al. Replicable and coupled changes in innate and adaptive immune gene expression in two case-control studies of blood microarrays in major depressive disorder. Biol Psychiatry. 2018;83:70-80.

62. Aberg KA, Shabalin AA, Chan RF, Zhao M, Kumar G, van Grootheest $\mathrm{G}$, et al. Convergence of evidence from a methylomewide CpG-SNP association study and GWAS of major depressive disorder. Transl Psychiatry. 2018;8:1-10.

63. Yu L, Chibnik LB, Yang J, McCabe C, Xu J, Schneider JA, et al. Methylation profiles in peripheral blood CD4+ lymphocytes versus brain: The relation to Alzheimer's disease pathology. Alzheimer's Dement. 2016;12:942-51.

64. Dunn EC, Wiste A, Radmanesh F, Almli LM, Gogarten SM, Sofer T, et al. Genome-wide association study (GWAS) and genome-wide by environment interaction study (GWEIS) of depressive symptoms in African American and Hispanic/Latina women. Depress Anxiety. 2016;33:265-80.

65. Okbay A, Baselmans BM, De Neve J-E, Turley P, Nivard MG, Fontana MA, et al. Genetic variants associated with subjective well-being, depressive symptoms, and neuroticism identified through genome-wide analyses. Nat Genet. 2016;48:624-33.

66. Zeng Y, Navarro P, Fernandez-Pujals AM, Hall LS, Clarke T-K, Thomson PA, et al. A combined pathway and regional heritability analysis indicates NETRIN1 pathway is associated with major depressive disorder. Biol Psychiatry. 2017;81:336-46.

67. Arnau-Soler A, Macdonald-Dunlop E, Adams MJ, Clarke T-K, MacIntyre DJ, Milburn K, et al. Genome-wide by environment interaction studies of depressive symptoms and psychosocial stress in UK Biobank and Generation Scotland. Transl Psychiatry. 2019;9:1-13.

68. Strawbridge RJ, Ward J, Ferguson A, Graham N, Shaw RJ, Cullen B, et al. Identification of novel genome-wide associations for suicidality in UK Biobank, genetic correlation with psychiatric disorders and polygenic association with completed suicide. EBioMedicine. 2019;41:517-25.

69. Wray NR, Ripke S, Mattheisen M, Trzaskowski M, Byrne EM, Abdellaoui A, et al. Genome-wide association analyses identify 44 risk variants and refine the genetic architecture of major depression. Nat Genet. 2018;50:668-81.

70. Broome MR, Saunders KEA, Harrison PJ, Marwaha S. Mood instability: significance, definition and measurement. Br J Psychiatry. 2015;207:283-5.

71. Ward J, Strawbridge RJ, Bailey ME, Graham N, Ferguson A, Lyall DM, et al. Genome-wide analysis in UK Biobank identifies four loci associated with mood instability and genetic correlation with major depressive disorder, anxiety disorder and schizophrenia. Transl Psychiatry. 2017;7:1-9.

72. Barbu MC, Zeng Y, Shen X, Cox SR, Clarke T-K, Gibson J, et al. Association of whole-genome and NETRIN1 signaling pathway-derived polygenic risk scores for major depressive disorder and white matter microstructure in the UK Biobank. Biol Psychiatry: Cogn Neurosci Neuroimaging. 2019;4:91-100.

73. Ward J, Lyall L, Bethlehem RA, Ferguson AA, Strawbridge RJ, Lyall DM, et al. Novel genome-wide associations for anhedonia, genetic correlation with psychiatric disorders, and polygenic association with brain structure. bioRxiv. 2019:656298.

74. Roberson-Nay R, Wolen AR, Lapato DM, Lancaster EE, Webb BT, Verhulst B, et al. Twin Study of Early-Onset Major Depression Finds DNA Methylation Enrichment for Neurodevelopmental Genes. bioRxiv. 2018:422345.

75. Smith DJ, Escott-Price V, Davies G, Bailey MES, ColodroConde L, Ward J, et al. Genome-wide analysis of over 106000 individuals identifies 9 neuroticism-associated loci. Mol Psychiatry. 2016;21:749-57.

76. Lee PH, Anttila V, Won H, Feng Y-CA, Rosenthal J, Zhu Z, et al. Genome wide meta-analysis identifies genomic relationships, novel loci, and pleiotropic mechanisms across eight psychiatric disorders. bioRxiv. 2019:528117.

77. Manolio TA, Collins FS, Cox NJ, Goldstein DB, Hindorff LA, Hunter DJ, et al. Finding the missing heritability of complex diseases. Nature. 2009;461:747-53.

78. Srour M, Riviere JB, Pham JM, Dube MP, Girard S, Morin S, et al. Mutations in DCC cause congenital mirror movements. Science. 2010;328:592-592.

79. Vosberg DE, Zhang Y, Menegaux A, Chalupa A, Manitt C, Zehntner S, et al. Mesocorticolimbic connectivity and volumetric alterations in DCC mutation carriers. J Neurosci. 2018;38: 4655-65.

80. Wing VC, Payer DE, Houle S, George TP, Boileau I. Measuring cigarette smoking-induced cortical dopamine release: a $[11 \mathrm{C}]$ FLB-457 PET study. Neuropsychopharmacology. 2014;40: 1417-27.

81. Venugopalan VV, Casey KF, O'Hara C, O’Loughlin J, Benkelfat $\mathrm{C}$, Fellows LK, et al. Acute phenylalanine/tyrosine depletion reduces motivation to smoke cigarettes across stages of addiction. Neuropsychopharmacology. 2011;36:2469-76.

82. Linnér RK, Biroli P, Kong E, Meddens SFW, Wedow R, Fontana MA, et al. Genome-wide association analyses of risk tolerance and risky behaviors in over 1 million individuals identify hundreds of loci and shared genetic influences. Nat Genet. 2019;51:245-57.

83. Kichaev G, Bhatia G, Loh P-R, Gazal S, Burch K, Freund MK, et al. Leveraging polygenic functional enrichment to improve GWAS power. Am J Hum Genet. 2019;104:65-75. 
84. Zanetti KA, Wang Z, Aldrich M, Amos CI, Blot WJ, Bowman $\mathrm{ED}$, et al. Genome-wide association study confirms lung cancer susceptibility loci on chromosomes $5 \mathrm{p} 15$ and $15 \mathrm{q} 25$ in an African-American population. Lung Cancer. 2016;98:33-42.

85. Khadka S, Narayanan B, Meda SA, Gelernter J, Han S, Sawyer B, et al. Genetic association of impulsivity in young adults: a multivariate study. Transl Psychiatry. 2014;4:e451.

86. Leyton M, Boileau I, Benkelfat C, Diksic M, Baker G, Dagher A. Amphetamine-induced increases in extracellular dopamine, drug wanting, and novelty seeking: a PET/[11C] raclopride study in healthy men. Neuropsychopharmacology. 2002;27:1027-35.

87. Jaworska N, Cox SM, Casey KF, Boileau I, Cherkasova M, Larcher $\mathrm{K}$, et al. Is there a relation between novelty seeking, striatal dopamine release and frontal cortical thickness? PLoS ONE. 2017;12:e0174219.

88. Morales M, Pickel VM. Insights to drug addiction derived from ultrastructural views of the mesocorticolimbic system. Ann N Y Acad Sci. 2012;1248:71-88.

89. Hibar DP, Stein JL, Renteria ME, Arias-Vasquez A, Desrivières $\mathrm{S}$, Jahanshad N, et al. Common genetic variants influence human subcortical brain structures. Nature. 2015;520:224-9.

90. Elliott LT, Sharp K, Alfaro-Almagro F, Shi S, Miller KL, Douaud G, et al. Genome-wide association studies of brain imaging phenotypes in UK Biobank. Nature. 2018;562:210-6.

91. Okada N, Fukunaga M, Yamashita F, Koshiyama D, Yamamori $\mathrm{H}$, Ohi $\mathrm{K}$, et al. Abnormal asymmetries in subcortical brain volume in schizophrenia. Mol Psychiatry. 2016;21:1460-6.

92. Luo N, Sui J, Chen J, Zhang F, Tian L, Lin D, et al. A Schizophrenia-Related Genetic-Brain-Cognition Pathway Revealed in a Large Chinese Population. EBioMedicine. 2018;37:471-82.
93. Sachs-Ericsson NJ, Hajcak G, Sheffler JL, Stanley IH, Selby EA, Potter GG, et al. Putamen volume differences among older adults: depression status, melancholia, and age. J Geriatr Psychiatry Neurol. 2017;31:39-49.

94. Koolschijn P, van Haren NE, Lensvelt-Mulders GJ, Pol H, Hilleke E, Kahn RS. Brain volume abnormalities in major depressive disorder: a meta-analysis of magnetic resonance imaging studies. Hum Brain Mapp. 2009;30:3719-35.

95. Arnone D, McIntosh AM, Ebmeier KP, Munafò MR, Anderson IM. Magnetic resonance imaging studies in unipolar depression: systematic review and meta-regression analyses. Eur Neuropsychopharmacol. 2012;22:1-16.

96. Schmaal L, Veltman DJ, van Erp TG, Sämann P, Frodl T, Jahanshad N, et al. Subcortical brain alterations in major depressive disorder: findings from the ENIGMA Major Depressive Disorder working group. Mol Psychiatry. 2016;21: 806-12.

97. Gong Q, Scarpazza C, Dai J, He M, Xu X, Shi Y, et al. A transdiagnostic neuroanatomical signature of psychiatric illness. Neuropsychopharmacology. 2019;44:869-75.

98. Edwards TJ, Marsh APL, Lockhart PJ, Richards LJ, Leventer RJ. Teaching NeuroImages: Imaging features of $D C C$-mediated mirror movements and isolated agenesis of the corpus callosum. Neurology. 2018;91:e886-7.

99. Cooper DN. Functional intronic polymorphisms: buried treasure awaiting discovery within our genes. Hum Genomics. 2010;4: 284-8.

100. Schoenfelder S, Fraser P. Long-range enhancer-promoter contacts in gene expression control. Nat Rev Genet. 2019;20: 437-55. 